\title{
Effect of Orthodontic Treatment in Occurrence of Dental Cories
}

\author{
Dr Sandhya Shrestha, ${ }^{1}$ Dr Lipika Shrestha, ${ }^{2}$ Dr Namita Shrestha, ${ }^{3}$ Dr Rabindra M Shrestha ${ }^{4}$ \\ .2.3Lecturer, Dept of Conservative Dentistry \& Endodontics, ${ }^{4}$ Asso Prof, Dept of Orthodontics \\ Kantipur Dental College, Kathmandu, Nepal
}

\section{ABSTRACT}

Introduction: Attaining improved aesthetics and proper occlusion are main reasons for commencing orthodontic treatment in any patient. However it is anticipated that orthodontic treatment increases the risk of carious lesions.

Objective: To analyze prevalence of dental caries in relation to gender, age group, duration of orthodontic treatment and malocclusion type; and to assess oral hygiene and food habit practice in Nepalese orthodontic patients.

Materials \& Method: A cross sectional study was done in 212 orthodontic patients (age range 11-30 years) having fixed appliance for at least six months duration. A survey form based on 'Dentition Status \& Treatment Need, WHO' was used to depict DMFT Index and prevalence of dental caries. A questionnaire was used to assess the practice of oral hygiene measures and food habits of the orthodontic patients. The association between dental caries and gender, age group, duration of orthodontic treatment and malocclusion type were analyzed using chi-square test $(\mathrm{p}<0.05)$.

Result: The prevalence of dental caries (DMFT) was $79.2 \%$ and mean DMFT value was 2.87 among Nepalese orthodontic patients. Occurrence of dental caries among male and female patients was $69.44 \%$ and $60 \%$ respectively. Caries occurrence was highest in age group 16-20 years (72.22\%), in more than 18 months treatment duration group (63.92\%) and in Class I malocclusion group (68.38\%). Similarly, 30.2\% consume sweets foodstuff, $26.9 \%$ consume junk food and $14.2 \%$ consume snacks in between meals frequently.

Conclusion: Fairly good proportion of Nepalese orthodontic patients practice normal oral hygiene methods but very few use special oral hygiene measures. The study showed no association between dental caries occurrence and gender groups, age groups, duration of orthodontic treatment and malocclusion types.

Key words: dental caries, DMFT, malocclusion, occurrence, orthodontic treatment, prevalence

\section{INTRODUCTION}

Dental caries is an infectious multifactorial microbiological disease that results in localized dissolution and destruction of calcified tissues of the teeth.' The orthodontic treatment can ascribe to inadequate removal or elimination of plaque and food debris from the restricted areas for clearance due to the appliance. , $^{3}$ Actually it needs more than the regular practice of brushing to maintain the oral hygiene in orthodontic patients. Majority of the patients involved in orthodontic treatment are adolescents and young adults, which is the generation having food pattern/ habit comprising mostly of junk food and consume more sweets and chocolates. These types of food habits serve as a major factor to cause multifactorial disease of tooth i.e. dental caries. ${ }^{4,5}$

The concept of trilogy (tooth, substrate, flora) of dental caries is explained well in caries prone orthodontic patients. ${ }^{6}$ The 'tooth' with braces, especially in young individuals offer plaque retention areas,' 'substrate' represent poor oral hygiene, lower clearance rate, more frequency of eating, high consumption of sticky and sweet food, low salivary $\mathrm{pH}^{8,9}$ and 'flora' is characterized by the accumulation of plaque with 
high microbial population. All these create ideal environment for development of dental caries with the effect of time. ${ }^{10}$

The present study aims to assess oral hygiene habits, food habits and prevalence of dental caries among Nepalese orthodontic patients. The study also analyzes the association of dental caries to gender, age group, malocclusion type and duration of orthodontic treatment.

\section{MATERIALS AND METHOD}

A cross sectional study was conducted among 212 orthodontic patients at the Orthodontic Departments of Kantipur Dental College \& Hospital and Samaj Dental Hospital, Kathmandu during March-May 2013. The sample patients treated with fixed orthodontic brackets by a single orthodontic specialist were included in the study. The age of the subjects ranged from 11-30 years, distribution of male and female were $34 \%$ and $66 \%$ respectively. Minimum duration of six months of the treatment was required to be included in the study. Subjects were categorized according to the duration of orthodontic treatment as; 6-12 months, 12-18 months and more than 18 months. Malocclusions were classified according to the Angle's classification."

A survey form with examination chart was developed comprising of general characteristics of the patient, duration of orthodontic treatment, Angle's classification of malocclusion. A questionnaire on oral hygiene and food habits was used. The dentition status was examined by using 'Dentition Status and Treatment
Need' as appraised by WHO oral health survey form 1997, ${ }^{12}$ which could depict the Decay, Missing, Filled Tooth (DMFT) Index.

The crown portion of the dentition was noted and the root part was excluded in the study as the root exposure in the targeted group is negligible. The Treatment Need part of survey form was not included in the present study. The buccal and lingual/palatal pits/caries on banded molars were excluded as the vision was obstructed by molar bands. Radiographic examination was not done to evaluate dental caries.

After the informed verbal consent, the examination was done using mouth mirror and WHO probe under sterilized condition in a dental chair with sufficient light. WHO criteria was used to assess DMFT index. ${ }^{12}$ For the reliability of data, all patients were examined by a single qualified dental professional. Statistical analysis was done by using SPSS version 16.0. The statistical analysis including frequency distribution, cross tabulation and chi-square test was used to find the association between dental caries and gender, age group, malocclusion type and duration of orthodontic treatment $(p<0.05)$.

\section{RESULT}

The present study comprised of 212 orthodontic patients including 140 (66\%) female and 72 (34\%) male. The age of the subjects ranged from 11 to 30 years with mean age 19.69 years. The frequency distribution of subjects with respect to gender and age group is given in Table 1 and duration of orthodontic treatment is shown in Figure 1.

Table 1: Distribution of subjects according to age and gender

\begin{tabular}{|c|c|c|c|c|c|}
\hline Age group (in years) & Male & Female & Total & Mean & Standard deviation \\
\hline $11-15$ & 21 & 28 & $49(23.1 \%)$ & \multirow{5}{*}{19.69} & \multirow{5}{*}{4.57} \\
\hline $16-20$ & 28 & 44 & 72 (34.0\%) & & \\
\hline $21-25$ & 18 & 52 & 70 (33.0\%) & & \\
\hline $26-30$ & 5 & 16 & 21 (9.9\%) & & \\
\hline Total & 72 & 140 & $212(100 \%)$ & & \\
\hline
\end{tabular}

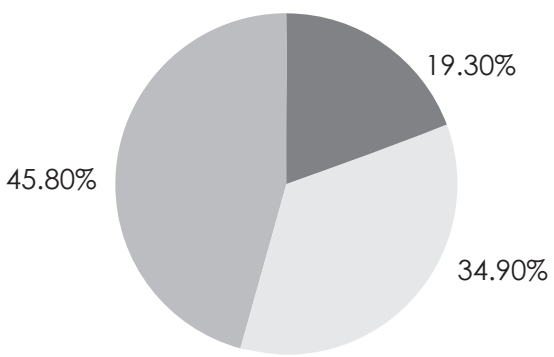

6-12 months

12-18 months

$>18$ months

Figure 1: Duration of orthodontic treatment 
The present study depicted the prevalence of dental caries (DMFT) as $79.2 \%$ (Figure 2) with the mean DMFT value 2.87 and a standard deviation 2.65. Among 212 patients, $63.2 \%$ had one or more carious tooth/teeth in the oral cavity. Occurrence of dental caries among male and female patients was $69.44 \%$ and $60 \%$ respectively. However, there was no statistically significant association in caries occurrence between gender groups (Table 2). A total of $46.2 \%$ participants had undergone tooth extraction due to other reasons; mainly for therapeutic orthodontic purpose.

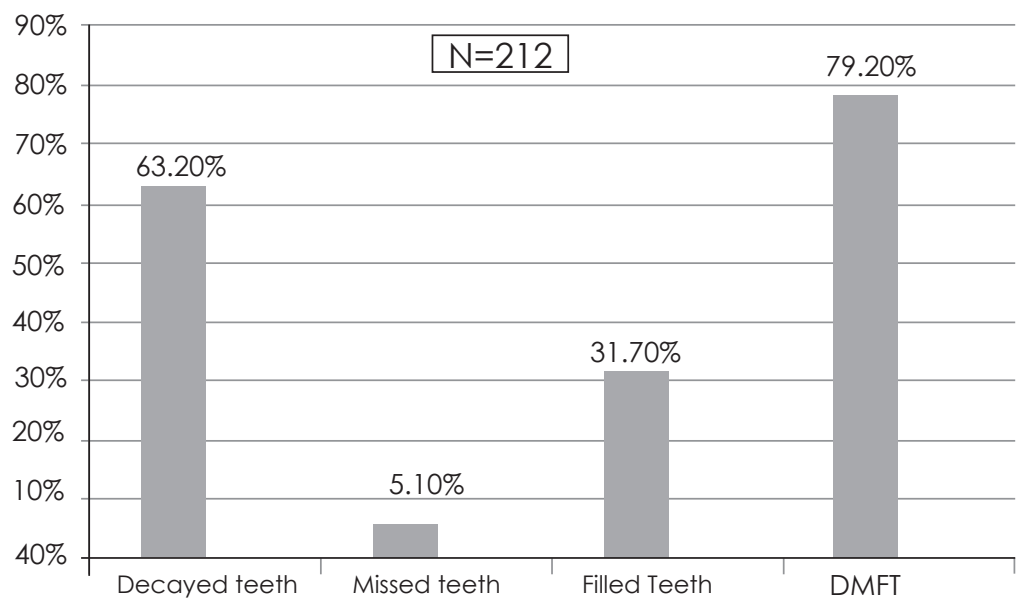

Figure 2: Prevalence of DMFT Index

Table 2: Cross tabulation between gender and dental caries

\begin{tabular}{|c|c|c|c|c|}
\hline \multirow{2}{*}{ Gender } & \multicolumn{2}{|c|}{ Carious teeth } & \multirow{2}{*}{ Total } & \multirow{2}{*}{$p$-value } \\
\hline & Absent & Present & & \\
\hline Male & 22 (30.56\%) & 50 (69.44\%) & 72 & \multirow{3}{*}{0.177} \\
\hline Female & 56 (40.0\%) & $84(60.0 \%)$ & 140 & \\
\hline Total & 78 (36.8\%) & $134(63.2 \%)$ & 212 & \\
\hline
\end{tabular}

The study showed that the distribution of caries occurrence was highest in age group 16-20 years i.e. $72.22 \%$. However, there was no association between the age group and occurrence of dental caries (Table 3). According to the duration of orthodontic treatment; subjects undergoing treatment for $6-12$ months duration had $58.54 \%$, 12 18 months had $64.86 \%$ and more than 18 months had $63.92 \%$ occurrence of dental caries. However, there was no association between the duration of orthodontic treatment and caries occurrence (Table 4).

Table 3: Cross tabulation between age group and dental caries

\begin{tabular}{|c|c|c|c|c|}
\hline \multirow{2}{*}{$\begin{array}{l}\text { Age group } \\
\text { ( in years) }\end{array}$} & \multicolumn{2}{|c|}{ Carious teeth } & \multirow{2}{*}{ Total } & \multirow{2}{*}{$p$-value } \\
\hline & Absent & Present & & \\
\hline $11-15$ & $16(32.65 \%)$ & 33 (67.35\%) & 49 & \multirow{5}{*}{0.92} \\
\hline $16-20$ & $20(27.78 \%)$ & $52(72.22 \%)$ & 72 & \\
\hline $21-25$ & $33(47.14 \%)$ & $37(52.86 \%)$ & 70 & \\
\hline $26-30$ & 9 (42.86\%) & $12(57.14 \%)$ & 21 & \\
\hline Total & $78(36.8 \%)$ & 134 (63.2\%) & 212 & \\
\hline
\end{tabular}


Table 4: Cross tabulation between duration of orthodontic treatment and dental caries

\begin{tabular}{|l|c|c|c|c|}
\hline \multirow{2}{*}{\multicolumn{1}{c|}{ Duration }} & \multicolumn{2}{c|}{ Carious teeth } & \multirow{2}{*}{ Total } & p-value \\
\cline { 2 - 4 } & Absent & Present & & \\
\hline 6-12 months & $17(41.46 \%)$ & $24(58.54 \%)$ & 41 & \multirow{2}{*}{0.782} \\
\hline $12-18$ months & $26(35.14 \%)$ & $48(64.86 \%)$ & 74 & \\
\hline$>18$ months & $35(36.08 \%)$ & $62(63.92 \%)$ & 97 & \\
\hline Total & $78(36.8 \% 0$ & $134(63.2 \%)$ & 212 & \\
\hline
\end{tabular}

In a total of 212 orthodontic patients, $55.2 \%$ had Class I, 36.3\% had Class II and $8.5 \%$ had Class III molar relation. The occurrence of dental caries was $68.38 \%$ in Class I, $57.14 \%$ in Class II and $55.55 \%$ in Class III patients. There was no significant association between the distribution of Angle's classification of malocclusion and caries occurrence (Table 5).

Table 5: Angle's classification of malocclusion and dental caries

\begin{tabular}{|c|c|c|c|c|}
\hline \multirow{2}{*}{ Angle's classification } & \multicolumn{2}{|c|}{ Carious teeth } & \multirow{2}{*}{ Total } & \multirow{2}{*}{$p$-value } \\
\hline & No & Yes & & \\
\hline Class I & 37 (31.62\%) & 80 (68.38\%) & 117 & \multirow{4}{*}{0.221} \\
\hline Class II & $33(42.86 \%)$ & $44(57.14 \%)$ & 77 & \\
\hline Class III & $8(44.44 \%)$ & $10(55.55 \%)$ & 18 & \\
\hline Total & 78 (36.8\%) & $134(63.2 \%)$ & 212 & \\
\hline
\end{tabular}

\section{Assessment of oral hygiene and food habits}

An assessment on oral hygiene habits among Nepalese orthodontic patients revealed that, $72.6 \%$ had the habit of brushing two to three times a day, $82.5 \%$ used normal tooth brush, $17.5 \%$ used orthodontic brush, whereas only $1.9 \%$ of the orthodontic patients used interdental brush. Among the participants, $90.1 \%$ had the habit of rinsing mouth after every meal, and $6.6 \%$ also used mouthwash (Table 6).

Table 6: Distribution of subjects according to oral hygiene habits

\begin{tabular}{|l|l|c|c|}
\hline \multicolumn{1}{|l|}{ Oral hygiene habits } & Once/day & Number & Percentage \\
\hline \multirow{3}{*}{ Brushing habit } & 2-3 time/day & $\mathbf{5 3}$ & $\mathbf{2 5 . 0}$ \\
\cline { 2 - 4 } & Irregular & 154 & 72.6 \\
\hline \multirow{3}{*}{ Type of tooth brush } & Normal toothbrush & 175 & 2.4 \\
\cline { 2 - 4 } & Orthodontic toothbrush & 37 & 17.5 \\
\hline \multirow{3}{*}{ Mouth rinsing habit } & Rinse after every meal & 191 & 90.1 \\
\cline { 2 - 4 } & Rinse irregularly after meal & 21 & 9.9 \\
\hline \multirow{2}{*}{ Additional oral hygiene aids } & Interdental brush & 4 & 1.9 \\
\cline { 2 - 4 } & Regularly use mouthwash & 14 & 6.6 \\
\hline
\end{tabular}

The food habits of the orthodontic patients showed that $30.2 \%$ consume sweets and chocolates frequently and $26.9 \%$ consume junk food frequently. Similarly, $14.2 \%$ participants consume snacks in between meals frequently (Table 7).

Table 7: Distribution of subjects according to food habits

\begin{tabular}{|l|c|c|}
\hline Food habits & Consume occasionally & Consume frequently \\
\hline Sweets/ chocolates & $148(69.8 \%)$ & $64(30.2 \%)$ \\
\hline Junk food & $155(73.1 \%)$ & $57(26.9 \%)$ \\
\hline Snack in between meals & $182(85.8 \%)$ & $30(14.2 \%)$ \\
\hline
\end{tabular}




\section{DISCUSSION}

There is difficulty in maintaining oral hygiene in orthodontic patients as the malposed teeth cause inconvenience in cleaning, which is further complicated by the fixed appliance component and frequent ulcerations. Plaque is a precursor of dental caries; and plaque retention sites are particularly prone to tooth decay. ${ }^{13}$ Hriday reported high accumulation of plaque in orthodontic patients. ${ }^{14}$ Various studies ${ }^{4,15}$ report high prevalence of dental caries in orthodontic patients which is also reflected in the present study. Among 212 patients examined, the prevalence of DMFT Index was $79.2 \%$ with mean DMFT value 2.87 . This result is not however consistent with the dental caries data of the Nepalese population sample. The prevalence of dental caries according to Nepal National Oral Health Pathfinder Survey ${ }^{16}$ (DMFT Index) was $25.6 \%$ in $12-13$ year, $26.3 \%$ in 15-16year and $57.5 \%$ in 35-45year cohorts.

Stahl et all ${ }^{17}$ studied DMFT values in primary and mixed dentition, whose mean values were 1.02 and 1.53 respectively. They found no positive correlation between prevalence of caries and malocclusion, which is similar to the present study on orthodontic patients. Mtaya et $\mathrm{al}^{4}$ showed mean Decayed, Missing, Filled Teeth, and DMFT were 1.7, 2.1, 2.4, and 1.7 respectively. The present study showed the mean DMFT as $0.63,0.05,0.30$ and 2.87 respectively. Martignon et $a^{15}$ in 12-29 years Colombian subjects receiving fixed orthodontic treatment showed mean DMF-S as 6.7. Interestingly, Nolting et $a l ; 18$ reported reduced DMFT scores after orthodontic treatment possibly as a result of convenience in maintaining oral health. These apparent differences in caries index scores may be due to variation in sample population, sample size and study design.

As per the scoring for caries status, the initial caries requiring pit and fissure sealant and restorative treatment were included and those requiring preventive treatment were considered as non-carious, hence white spots or surface lesions without cavitation were excluded. Richter et $a^{19}$ reported the incidence of white-spot lesions during orthodontic treatment in $72.9 \%$ subjects, which was later developed to cavitated lesions in $2.3 \%$. This report necessitates the determination of white-spot lesions as well in orthodontic patients.

Change in oral environment that favours plaque accumulation and retention increase the risk of developing caries. Orthodontic treatment is implicated for altering the oral environment by providing retention sites for dental plaque. ${ }^{13}$ The present study showed lesser prevalence of caries in the initial stage compared to later stages of orthodontic treatment. Ahmed et $a^{20}$ found increased prevalence of caries with the time period of orthodontic treatment. According to their report, the prevalence of caries was 33\% in 6 months and $61 \%$ in 12 months duration of treatment.

As for the age group distribution, the present study reveals that the younger age groups of 11-20 years showed higher caries prevalence than older age groups. Mtaya ${ }^{4}$ also showed that younger patients are at higher risk for caries development than the adults.

As per the data on oral hygiene practice by orthodontic patients, about two-third of patients brush two or more times a day and more than ninety percent patients rinse mouth after every meal. However with special consideration to orthodontic appliance, only $17.5 \%$ use orthodontic brush, $1.9 \%$ use interdental brush, $6.6 \%$ use medicated mouthwash; which are expected of all orthodontic patients. The adverse food habits which contribute to dental caries; $30.2 \%$ consume sweets and chocolates, $26.9 \%$ consume junk food and $14.2 \%$ consume snacks in between meals regularly.

\section{CONCLUSION}

The dental caries (DMFT) prevalence was high up to 79.2\%; however mean DMFT value was 2.87 in Nepalese orthodontic patients. The occurrence of untreated dental caries was 63.2\%; which was highest in younger age group and at the later stages of orthodontic treatment. Large proportion of orthodontic patients consume sweets foodstuff, junk food and snacks in between meals and very few patients practice special oral hygiene measures.

Well aligned teeth are not only aesthetically pleasant but also help to maintain proper oral hygiene and decrease occurrence of dental caries. Patient motivation to maintain oral hygiene with the use of orthodontic brush, interdental cleaning aids and fluoride mouthwash/tooth mousse help in reducing carious lesions. Periodic evaluation of dental caries must be done in orthodontic patients.

\section{ACKNOWLEDGEMENT}

We would like to thank Dr Sujita Shrestha, Dept of Community \& Public Health Dentistry, KDCH for her assistance in statistical analysis, Dr Rashmi Shakya for her assistance in data collection, to the patients, all the staffs and interns of departments of Periodontics and Orthodontics.

OJN 


\section{REFERENCES}

1. Roberson TM. Cariology: The lesion, etiology, prevention and control. Sturdevant's Art \& science of operative dentistry 2006; 5nd ed. Mosby, Elsevier.

2. Anas H, Mullaa AL, Kharsab Saad Al, Kjellbergc H, Birkhedd D. Caries risk Profiles in Orthodontic patients at follow-up using cariogram. Angle Orthodontist 2009; 79:2: 323.

3. Bourzgui F, Sebbar M, Hamza M. Orthodontics and Caries. Department of Orthodontics, Faculty of Dentistry, University of Hassan Il Ain Chok, Casablanca, Morocco.

4. Mtaya M, Brudvik P, Astrom AN. Prevalence of malocclusion and its relationship with sociodemographic factors, dental caries, and oral hygiene in 12- tol4-year-old Tanzanian schoolchildren.European Journal of Orthodontics 2009. 31: 467-476.

5. Vander Veen MH, Attin R, Schwestka-Polly R, Wiechmann D. Caries outcomes after orthodontic treatment with fixed appliances: do lingual brackets make a difference? Eur J Oral Sci 2010; 118:298-303.

6. Charland, R.; Voyer, R.; Cudzinowski, L.; Salavail, P. \& Abelardo, L. La carie dentaire: étiopathogénie, diagnostic et traitement: encore beaucoup à découvrir. J. Dent.Québec 2001; 38:409-416.

7. MCDonald SP, Sheiham A. The distribution of caries on different tooth surfaces at varying levels of caries- a compilation of data from 18 previous studies. Community Dental Health 1992; 9:39-48.

8. Haïkel Y. Thérapeutique étiopathogénique de la carie. Encycl Méd Chir, Stomatologie et Odontologie 2001, 23-010-F-10, p 21.

9. Droz D, Blique M. Contrôle du risque alimentaire et prophylaxie dentaire individuele enomnipratique, lère partie: Connaître les facteurs de risque essentiels pour mieux les identifier. Poser le problème de l'alimentation cariogène. Inf Dent 1999; 81:20:1 40511.

10. Rillard F, Khelifa N, Colon P. Données actuelles sur la pathogénie de la maladie carieuse. Rev Odontosomatol, Tome 29:4:189196.

11. Angle EH. Treatment of malocclusion of the teeth. Angle's system. Philadelphia: S S White Dental Manufacturing Company; 1907.

12. World Health Organization. Oral health surveys: Basic Methods. 4th ed. Geneva: WHO; 1999.

13. Qazi HS, Azam S, Khurram MS, Zia AU. Prevalence of dental caries in the permanent dentition of patients seeking orthodontic treatment in Bara Kahu. Pakistan Oral \& Dental Journal 2011;31:2.

14. Hriday RP, Ahmed AH, Banu N, Kumar S, Kumar M, Dharmashree.S, Jeevika C. Plaque, caries level and oral hygiene habits in patients receiving orthodontic treatment. International Journal of Preventive Dentistry and Oral Epidemiology 2012; 1:1:1-6.

15. Martignon S, Ekstrand KR, Lemos MI, Lozano MP, Higuera C. Plaque, caries level and oral hygiene habits in young patients receiving orthodontic treatment. Community Dent Health. 2010;27:3:133-8.

16. Yee R, Mishra P. Nepal National Oral Health Pathfinder Survey 2004: Oral Health Focal Point, Ministry of Health, HMG Nepal, 2004.

17. Stahl F, Grabowski R. Malocclusion and caries prevalence: is there a connection in the primary and mixed dentitions? Clin Oral Investig. 2004; 8:2:86-90.

18. Nolting I, Karin M, Ruf S. Dental heath \& orthodontic treatment need among dental students treated by certified orthodontist and general dental practioner. Quintessence Int 2008; 39:1:73-7.

19. Richter AE,Arruda AO, Peters MC, Sohn W.Incidence of caries lesions among patients treated with comprehensive orthodontics. Am J Orthod Dentofacial Orthop .2011;139:5:657-64.

20. Ahmed I, Haque S, Nazir R. Carious lesions in patients undergoing orthodontic treatment. J Pak Med Assoc 201 1; 61:12:1176-9. 